\title{
NOTE ON THE COMPOSITION OF SOME PREPARATIONS SOLD AS HOP- SUBSTITUTES.
}

By A. H. Allen and W. Chattaway. Read at the Meeting, May, 1887.

THE detection of hop-substitutes in beer is so intimately connected with the question of the nature of the hop-substitutes actually employed, that we have thought it of importance to examine some of those preparations most extensively advertised. We have been struck with the great difference in the price and the physical appearance of the advertised hop-substitutes. Time has not allowed us to make so full an examination of the chief advertised preparations as we could have wished, but the following observations will be of interest.

In sample $A$, by examination with a lens, quassia, chiretta, and hops were recognised without difficulty. There was also present a seed not unlike that from a cruciferous plant, the exact nature of which was not identified.

Sample B was of a very extraordinary character. It consisted largely of rosin mixed with catechu or cutch, or some closely analogous tannin extract. Considerable quantities of fish-gelatin and chiretta were also present, and sodium sulphite was detected in addition. Whatever may be the value of fish-gelatin, sodium sulphite, and tannin, in the manufacture of beer, they can hardly be legitimately termed "hopsubstitutes." The object of adding rosin is not very apparent; possibly it may have been an attempt to replace hop-resin, in which case truly a little knowledge is a dangerous thing. The proportions of the several constituents of this sample may be inferred from the following statement of the results of its treatment by solvents, etc. :-

Moisture, driven off at $100^{\circ} \mathrm{C}$. $\quad \ldots \quad \ldots \quad \ldots \quad \ldots \quad \ldots \quad 8.5$ per cent.

Ether extract, consisting of nearly pure colophony .. . . $36.3 \quad$ " ",

Alcoholic extract, chiefly tannin and other constituents of cutch 16.6 " "

$\begin{array}{lllllllll}\text { Aqueous extract } & \ldots & \ldots & \ldots & \ldots & \ldots & \ldots & 27 \cdot 3 & \text { " }\end{array}$

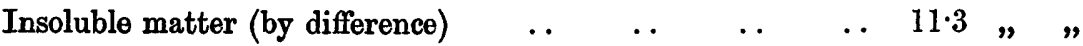

$$
\text { Ash } \quad \ldots \quad \ldots \quad \ldots \quad 10.0 \text { per cent. }=
$$

We have examined the other samples of advertised hop-substitutes less completely. Quassia was distinctly recognised in the decoctions of two, and other bitter substances were also present. No picric acid or calumba was present in any case. Pyrethrum ("Persian insect powder") was almost certainly a constituent of one preparation.

A curious difference is observable in the prices charged by the manufacturers of 
the advertised hop-substitutes. Thus the equivalent of $16 \mathrm{lbs}$. of hops was $3 \mathrm{~s} ., 4 \mathrm{~s} ., 4 \mathrm{~s}$., 4s. $2 \mathrm{~d}$., and $9 \mathrm{~d}$. respectively. So far as we can judge from the extent of our examination, the quality and suitability of the advertised hop-substitutes for their intended purpose is by no means to be gauged by the relative amounts charged for them.

With regard to the alleged injurious character of hop substitutes we are not in a position to offer any personal opinion. Picrotoxin, the active principle of cocculus indicus, we all know to have marked poisonous properties, and we should probably agree in regarding picric acid as an objectionable addition to beer. It is within our knowledge that picric acid formed an ingredient of a well-known hop-substitute some years since. Of course, its detection in beer presents no difficulty. There is no recent authentic record of the use of picrotoxin in beer, but there are some curious facts which go in that direction. There is no legitimate use for cocculus indicus in the arts or medicine,* and we are not aware of its receiving any application as a poison for the lower animals, except by fish poachers. According to Dragendorff, who was formerly chemist to the St. Petersburgh police, cocculus indicus has been largely used for adulterating beer in Russia, and brewers have been frequently fined for the practice and the beer confiscated. Schubert, of Wurzburg, has stated that Bavarian beer has been often adulterated with cocculus indicus. We find the statement that in a discussion in the House of Commons (date not stated) Lord E. Cecil said that the quantity of cocculus indicus imported into England in 1857 amounted to $68 \mathrm{cwt}$.; in 1867, the quantity had increased to $689 \mathrm{cwt}$.; and "last year," that it amounted to $1064 \mathrm{cwt}$. These amounts are not large, and may possibly have received some legitimate application, but the greater part was probably re-shipped.

As to quassia, there seems to be a general opinion in its favour as one of the least objectionable of hop-substitutes. Systematic experiments with quassiin are, however, almost wanting, except those of Campardon, referred to in the following extract from page 1264 of the " National Dispensatory," by Stille and Maisch :--

"Quassia is fatal to flies, and is sometimes used to preserve botanical collections from the ravages of insects. Rabbits and dogs have been killed by a concentrated preparation of the drug, the latter even by its application to the raw skin, and when its effects were not fatal it produced a partial paralysis of the limbs. Its bitter taste is more intense than that of most other stomachic tonics; like them, it excites the appetite for food and quickens digestion, but if too long continued it produces derangement of the stomach. Quassia may exhibit poisonous qualities, as in the following case:-A concentrated infusion of the drug was by mistake given in enema to a child four years old. Within an hour the child became unconscious and collapsed, the head was thrown back and the pupils were contracted, the respiration was inaudible, and the pulse could not be felt. It was restored by alcohol, ether, and ammonia (Medical Record, xviii. 404). The following conclusions were reached by Campardon in regard to quassiin-crystallised and amorphous (Bull. de Thér. ciii. 385). In moderate doses it increases the secretion of the saliva, the bile, the urine, and perhaps of the milk. It stimulates the excretory ducts of the several organs producing these secretions. In appropriate cases of sickness it quickens the appetite, renews the strength, facilitates the excretions, renders defecation

* It is an ingredient of an ointment which finds a very limited use. 
easier, and hastens the expulsion of renal and biliary calculi. Its toxical action resembles that of the convulsing poisons. $2 \frac{1}{2}$ grains (gm. $\left.0 \cdot 15\right)$ of amorphous, or $\frac{1}{4}$ grain (gm. 0.015) of crystallised quassiin will occasion the following symptoms :-A burning in the throat and æsophagus, and a sense of constriction in the former ; frontal headache; epigastric weight and pain; nausea, vertigo, confused vision, extreme restlessness and feverish impatience; unsteadiness of mind; frequent urination, loose stools, and vomiting ; cramps and spasms in the muscles of the lower limbs."

Considering the small proportion of quassiin which is required to impart a bitter taste to beer, it is questionable if it would ever be taken in practice in sufficient quantity to produce toxic effects.

We have ascertained by experiment that a solution of 1 part of crystallised quassiin in 500,000 parts of water has a strong and persistent bitter taste.

\section{Discussion.}

Dr. ADAms said that he worked on the question of hop-substitutes some ten or twelve years ago, and he found no difficulty in distinguishing between the bitter of hop and the substitutes used for it. The method he found most useful was the precipitation by sub-acetate of lead, and there was no difficulty at all with the ordinary bitters such as quassia, calumba, gentian, chiretta, and wormwood, all remaining in solution, whilst the bitter of hop, and also the bitter of the camomile, which behaves like the hop, goes down and leaves the solution bitterless. He had specimens of all the hop-substitutes in use in England at that time, and without a single exception the solution remained bitter after treatment with the sub-acetate of lead.

After having separated the filtrate and evaporated it down, there was no difficulty in detecting the bitter; but he did not think there was any possibility of distinguishing between the individual bitters, considering the minute quantity present, and one could only positively say there was another bitter present besides that of the hop.

Dr. MUTER said that, with regard to the question of the detection of bitters in beer, he would say at once that he did not quite share the President's views as to there being no difficulty in detecting and identifying them. It was a subject that he had worked at in former years in connection with his book on Materia Medica. He had made numerous experiments himself, and he had repeated many of the published experiments, and he could prognosticate that, as the President went along, he would meet with several published reactions, which were partially incorrect and perfectly misleading. Although a few bitters would be found to be comparatively easy of detection-quassia, for instance, was a bitter which spoke very much for itself-many of them were, to a great extent, involved in difficulty and obscurity at the present time. There was no branch of chemistry that so much undesirable matter had been published about as that relating to Materia Medica, and many of the older researches were incorrrect. No doubt one cause of this was that nowadays they had much better analytical appliances than the men who made these experiments. He did not for a moment mean to say that they were now cleverer than past observers, but for instance, they could not wash lead and other similar intractable precipitates in former days as one could now do by the aid of the filter pump, and the colour reactions for more than one proximate principle, which were given in books, were really not due to the principle at all, but to the traces of reagents and other matters that remained with them owing to the imperfect washing, which was almost certain to occur before the days of filter pumps. He was afraid that until the President, and others who might take the subject up, 
had had time to work it out by the aid of modern appliances, it would be going too far to say they could swear positively that a sample contained no hop-substitute.

Mr. AlLEN said he thought they could tell whether it contained hops or a substitute for hops.

Dr. Muter said then in that case how would they get on in cross-examination, seeing that they could not name the substitute? He did not remember how he first became acquainted with the lead process, but he believed that he could put his hands on it now. It must be quite thirteen or fourteen years ago since it was first published. Immediately it was brought out he had made experiments upon it, working on large quantities. Since that there had really been no other process that he knew of. He himself had used a process very similar to that mentioned, viz., precipitation with sub-acetate of lead, syphoning off the clear liquor after settlement, removing the excess of lead from this liquid, concentrating and tasting, and then extracting with immiscible solvents.

Now came a difficulty which shook his faith in his powers as an analyst as regards hop-substitutes. He had always believed in the process-from practising upon beer with various added bitters-until some time ago he got a beer which he was privately assured by the maker to have no bitter other than hops. This sample he put through the process, and he got a bitter out of that beer with chloroform after lead. He worked on a fairly large quantity, but the process here showed bitters other than hop, although he was assured that the sample represented as pure a beer as could possibly be obtained. Another difficulty was the quantity they might have to work on. Supposing an inspector brought them one-half or one-third of a pint, where was the process they could use? He had put bitters in the beer and worked on such quantities and failed to find them. In a case he knew of some time ago, there was some difficulty about some strychnine that was put in beer; he was aware of the very small quantity that had been put in because the chemist who had been stupid enough to lend himself to such a transaction had informed him of it. He made up some beer and divided it into two portions ; tried for extraneous bitters in one portion by the regular beer way and there was not a sign of it; he then tried the other portion with a special toxicological process for strychnine and found it. He had, even then, to use eight ounces of the beer for this purpose, to get a really satisfactory ordinary reaction. In the present state of chemical knowledge, it would not be, in his opinion, safe to say they could detect any amount of added bitters to beer, however small, and go to the length of naming those bitters on the quantity they would have usually brought to them by an inspector. With a gallon of beer and an unlimited fee covering many days' work, they might, however, be able to do something satisfactory towards it.

Dr. Dupre said he wished to protest strongly against the idea that a public analyst was always bound to make an analysis on only a few ounces of beer. He ought to have such a quantity as would enable him to certify the result with moral certainty. In his district he had only to write and get any quantity he wished for. No public analyst could be requested to make an analysis with a quantity which he himself believed to be utterly inadequate, and if any private person brings an insufficient quantity it is the analyst's plain duty to tell him so. As to strychnine, he might point out a case which occurred to him some years ago. A man, who had been wounded in India some time before, drank a glass of beer; he felt ill directly after, and went to a doctor, at whose house he had several tetanic convulsions. All he (Dr. Dupré) had to examine was the handkerchief with which the man had wiped his mouth, and the question was, had any strychnine been in the beer or not? He cut out some spots which looked like dried saliva, and worked upon them by the usual toxicological methods, but failed to detect 
strychnine. He next added a minute fragment of bichromate to a portion of the suspected extract, and carefully evaporated it on a microscope slide, and finally, while looking at it with a 1-inch power, he added a drop of sulphuric acid, and the strychnine came out most beautifully. Referring to the microscope, Dr. Dupré said that he was afraid chemists, as chemists, were not in the habit of using it as much as they ought.

Dr. Muter, in reference to Dr. Dupré's remarks, begged permission of the chair to say that if the majority of public analysts acted in the way indicated by him, they would find themselves in very bad odour with the local authorities. If an inspector were told to always buy a gallon or two of beer, instead of the usual pint or quart, he would reply that the vendor would at once suspect him, and declare the article, and so the purchase would be rendered nugatory for the purposes of the Act, and the money of the public wasted. As regards the application of delicate and tedious toxicological processes to beer in every case, there would then have to be a revision of the fee of $10 \mathrm{~s}$. $6 \mathrm{~d}$. per analysis laid down by the Act. It was one thing to analyse directly for a specifically suspected poison, and quite another matter to generally examine an article for adulteration for $10 \mathrm{~s}$. $6 \mathrm{~d}$.

Mr. Salamon said that he should like to hear some views about the varying extractive influences of different brewing-waters upon hops. It was well known, for instance, that waters containing sulphate of soda had a different influence to waters containing sulphate of $\operatorname{lime}$, and he thought it would be well for them, before dogmatising upon what would be a public question (because analysts would be called upon to distinguish these bitters), to ascertain, if possible, whether the varying salts in waters did exercise any influence upon the bitter itself. It might not be improbable that the case which Dr. Muter had mentioned fell within that category, and that it was an altogether different bitter which was extracted by the two waters.

With reference to the question of tannin, he might state, with accuracy, that not only had he to analyse a number of products coming from brewers, but he also had to go to the breweries and actually inspect the beer in process of manufacture.

In the year of the hop famine (1882) no doubt hop-substitutes were used to a large extent, but at present he did not know of a single brewery that used them, and it would be idle for them to do so with hops at the price at which they now were, but what they did use in a good many instances was tannin. He knew of some breweries where they used the most expensive hops they could buy ; and yet, in producing a beer full flavoured, round on the palate, and low in alcohol, and in order to get the nitrogenous matter out of the beer, he had known extract of cutch, or catechu, to be used, for the purpose of precipitating the nitrogenous or albuminous matter, but that could not be termed a hop-substitute.

Another point they must bear in mind; he did not want to take a political side on the question at such a meeting, but the low price of hops was not produced by hopsubstitutes, but by competition from abroad.

There was a general opinion among brewers, which was borne out by Dr. Graham, that hops had more to do with the drowsiness produced by beer drinking than alcohol, and there was consequently a tendency to reduce the amount of hops which they used, and to do that they sometimes used the cutch to which he had alluded.

In his opinion, this was rather a question as between brewers and hop-growers. If the brewers cared to come to a compromise with the growers- if the brewers like to say they will help their friends, the hop-farmers, then by all means let them do so.

They should be very careful in trying to compel brewers to use hops, whether they liked it or not. It would be absolutely impossible for thom, as a body of chemical analysts, to prove that these hop-substitutes were more injurious than the hop itself. 
Medical men would say that all these hop-bitters were less injurious to the system than the hop-bitter itself. It was evident from the present state of their knowledge that hopsubstitutes are little used, and if used at all are harmless in beer, and he would recommend that the question should be threshed out as between the brewers and the hop-growers.

Mr. R. Norton, M.P. for Tunbridge, as a visitor, expressed the great pleasure it had afforded him to be present, and, in reference to Mr. Salamon's last remarks, said that was not the position which was being taken up by the counties of Kent and Sussex. They felt that for a long time they were getting beer bittered with hops, but that now substitutes were used when hops were dear.

The generality of the public were under the impression that the beer was bittered with hops. It might be right or wrong, but at any rate they were under that impression, and in accordance with the Act the article should be supplied as demanded by the purchaser.

He wished that when a man went into a public-house, he should know whether the beer was bittered with hops or quassia; that was the point. $\mathrm{H}_{\theta}$ had listened with great pleasure to the debate there that night.

$\mathrm{He}$, now, understood, first, that it was possible to say whether there was any other ingredient than the hop present, and secondly, if so, whether that ingredient was quassia or not.

They would now be in a position to take half a gallon of beer from any brewery, and say, "This is not bittered with hops." That was the main thing they had been contending for-they did not care whether analysts were able to say what the bitter was, whether camomile or gentian. They had reason to know that quassia has been very largely used.

Analysts could help him and his friends to that extent, if they were unable to come to the friendly compromise with the brewers which they were trying for. There were three or four millions of capital embarked in the hop industry, and they desired to know whether hops were wanted or not. If every time hops were over a certain low standard of value the brewers were to use substitutes, it was obvious that a crop which cost $£ 40$ an acre to produce, could not be continued under these conditions.

Mr. Allew, in reply: If he had an insufficient quantity of any sample, he certified that the quantity was insufficient for him to form an opinion.

He understood Mr. Norton to consider it of great importance that they should be able to distinguish between "hops" on the one side, and " not hops" on the other; this he believed could be done with certainty, ease, and on a very moderate quantity of beer. As to the identification of the various hop-substitutes, he did not profess to be able to distinguish all, but he thought he could already positively recognise calumba, quassia, colocynth, and some other bitters, including picric acid and picrotoxin, and if the matter became important he believed in a year or two public analysts would have devised methods for the detection of the other bitters, just as they had conquered other analytical difficulties when the occasion arose.

With butter they did not say with what fat it was mixed, but simply that it contained foreign fat ; and they could do similarly with beer-that is, certify that it was beer; it contained a foreign bitter. As to tannin he would not admit that it was a bitter; it was an astringent, and if used in excess would simply make the beer nasty. It was not a hop-substitute; then why should it be used as an ingredient of a hopsubstitute? It just showed that those gentlemen who were buying hop-substitutes did not get what they expected. 